\title{
Influence of Zinc oxide films structure on biological protein adsorption for SAW biosensors
}

\author{
Qiuyun Fu, Jianfeng Deng, Dongxiang Zhou, Shuping Gong, Shujing Zhong and Wei LuO \\ Engineering Research Center for Functional Ceramics of the Ministry of Education, Department of \\ Electronic Science \& Technology, Huazhong University of Science \& Technology, \\ No. 1037 Luoyu Road, Hongshan District, Wuhan City 430074, P. R. China \\ hustluowei@gmail.com
}

\begin{abstract}
:
Zinc oxide films used for $\mathrm{ZnO} / \mathrm{SiO}_{2} / \mathrm{Si}$ based surface acoustic wave (SAW) Love mode sensors, were fabricated. $\mathrm{ZnO}$ films surface structure will affect the adsorption of the biological protein on the surface, which has an influence on the sensitivity of the SAW sensors. The structural properties of $\mathrm{ZnO}$ films prepared by RF magnetron sputtering have been characterized by Thornton's structure zone model. The X-ray diffraction (XRD) patterns show that the films are highly oriented with their crystallographic c-axis perpendicular to the substrate. Bovine serum albumin (BSA) was fixed to the surface of $\mathrm{ZnO}$ films. Then the mass of the adsorption proteins was examined by AFM to find out the optimum $\mathrm{ZnO}$ films structure for biological protein adsorption.
\end{abstract}

Key words: ZnO films structure; BSA; Protein adsorption;

\section{Introduction}

Zinc oxide $(\mathrm{ZnO})$ is a wide band gap $(\mathrm{Eg}=3.37 \mathrm{eV})$ semiconductor with important piezoelectric and electronic properties. Due to its large specific surface area, good biocompatibility, chemical stability, biomimetic and high electron mobility features, Nanostructured $\mathrm{ZnO}$ has attracted much attention in biosensors research field. In addition, the $\mathrm{ZnO}$ with a high isoelectric point (IEP $=9.5)$ is suitable for the adsorption of low IEP proteins, and is a very promising material for applications in biosensors based on the mass loading $[1,2,3]$. A kind of SAW biosensors based on $\mathrm{ZnO} / \mathrm{SiO}_{2} / \mathrm{Si}$ was reported by Soumya Krishnamoorthy and Thaleia Bei $[4,6]$.But the influence of Zinc oxide films structure on biological protein is not clear.

In this paper, $\mathrm{ZnO}$ thin films with different structural properties were deposited on $\mathrm{SiO}_{2}$ $(50 \mathrm{~nm}) / \mathrm{Si}(100)$ substrates by changing $\mathrm{Ar}$ pressure according to Thornton's structure zone model [3] by RF magnetron sputtering, which is possible to obtain good orientation and uniform films close to single-crystal morphology even on amorphous substrate or at low substrate temperature $[6,7,8]$. XRD and SEM were employed to observe the surface microstructure of films, Bovine serum albumin (BSA), which was widely used as a bridge to other proteins in biochemical tests, was chosen as a sample to study the Influence of Zinc oxide films structure on biological protein adsorption. BSA was fixed to the surface of $\mathrm{ZnO}$ thin films, and the adsorption of BSA was checked by AFM. In Further research, $\mathrm{ZnO}$ films would be used as piezoelectric film in $\mathrm{ZnO} / \mathrm{SiO}_{2} / \mathrm{Si} \mathrm{SAW}$ biosensors.

\section{Experiments}

1. $\mathrm{ZnO}$ films fabrication

$\mathrm{ZnO}$ films were deposited on $\mathrm{SiO}_{2}(50 \mathrm{~nm}) / \mathrm{Si}$ (100) substrates by RF magnetron sputtering system using a $\mathrm{ZnO}$ target $(99.9 \%)$. The substrates were thoroughly cleaned with deionized water, ethanol and dried before loading in the sputtering system. The distance between the target and the substrate was 70 $\mathrm{mm}$. The chamber was pumped down to $5 \times 10^{-4}$ $\mathrm{Pa}$ by a turbomolecular pump. The substrate and the chamber wall were grounded and the substrate holder was heated from room temperature to $250^{\circ} \mathrm{C}$ before deposition. Throughout all experiments, the target was presputtered for 10 mins under 100W RF power before the deposition to delete any contamination on the target surface. The films were grown at $250^{\circ} \mathrm{C}$, power of $100 \mathrm{~W}$ and $\mathrm{Ar}$ pressure of 0.2-3.2 $\mathrm{Pa}$ for studying the changes 
of the structural properties of $\mathrm{ZnO}$ thin films, which have been characterized in Thornton's structure zone model (Fig.1). The $\mathrm{ZnO}$ films were annealed at $900^{\circ} \mathrm{C}$ for $1 \mathrm{~h}$. The heating rate is $150{ }^{\circ} \mathrm{C} / \mathrm{h}$ from room temperature to annealing temperature. The crystallographic structure of the $\mathrm{ZnO}$ films was analyzed by XRD and SEM.

2. Surface activation and immobilization process

The $\mathrm{ZnO}$ films were activated by hydroxylation and followed by silanization with 3-aminopropyltriethoxysilane (ATES), used as the bridge to which gluteraldehyde is bound. Then BSA was immobilized on the surface of the $\mathrm{ZnO}$ films, which is used as a bridge to bind different proteins,and the mass of BSA were examined.

The $\mathrm{ZnO}$ films were washed several times with ethanol and deionized water. Then, the samples were immersed in ATES solution for $4 \mathrm{~h}$ at room temperature. The silanized devices were washed many times with ethanol and deionized water and baked at $110^{\circ} \mathrm{C}$. The silanized samples were then immersed in a $2 \%$ gluteraldehyde solution in $10 \mathrm{mM}$ sodium phosphate-buffered saline (PBS) at $\mathrm{pH} 7.4$, and shaken for $12 \mathrm{~h}$ at $4^{\circ} \mathrm{C}$. The samples were washed many times with deionized water. The samples were immersed in BSA in PBS solution and incubated shaking for $12-18 \mathrm{~h}$ at $4^{\circ} \mathrm{C}$, then rinsed several times in $10 \mathrm{mM}$ of PBS, rinsed in ultra pure water, and dried in $\mathrm{N}_{2}$ gas.

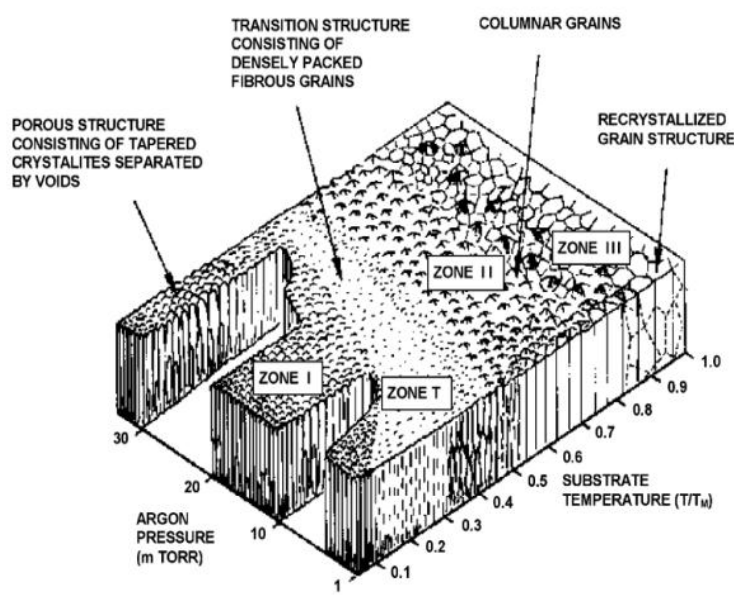

Fig. 1 Thornton's structure zone model for sputtered films on substrate temperature and argon pressure.

\section{Results and discussion}

1. Crystallization quality and film microstructure

XRD was employed to characterize the nano$\mathrm{ZnO}$ films. Fig. 2 shows the X-ray $\theta-2 \theta$ diffractogram of $\mathrm{ZnO}$ film deposited on $\mathrm{SiO}_{2} / \mathrm{Si}$ substrate with $\mathrm{Ar}$ pressures $1.2 \mathrm{~Pa}$. We observed that all of $\mathrm{ZnO}$ films have a strong diffraction peak of (002) at $2 \theta$ value of 36.48 , independent of Ar pressure. The presence of a strong diffraction peak of (002) indicates that films have a (002) preferred orientation (c axis).

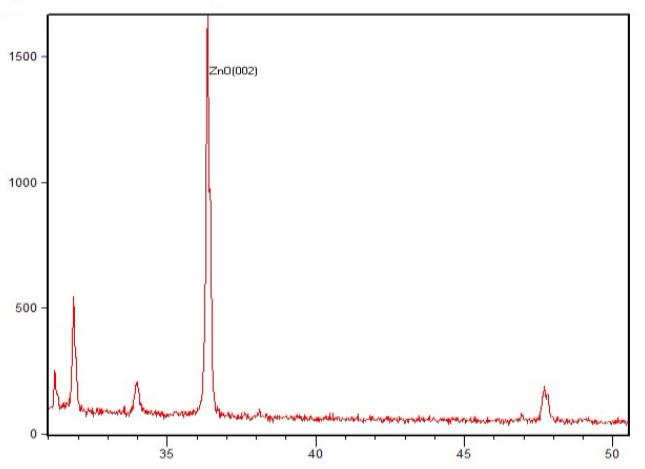

Fig. 2 XRD spectra of $\mathrm{ZnO}$ film deposited on $\mathrm{SiO}_{2} / \mathrm{Si}$ at $250{ }^{\circ} \mathrm{C}$, RF power $100 \mathrm{~W}$ and Ar pressure of 1.2 $\mathrm{Pa}$

The scanning electron microscopy (SEM) photographs of these films have been taken to evaluate their surface morphology and microstructure. As shown in Fig. 3, film's microstructure is in agreement with the trend given by Thornton's structure zone model, which was proposed by Movchan and Demchishin and extended by Thornton in Fig. 1. In the structure zone model, the surface structure was classified in term of four zones as a function of $\mathrm{T} / \mathrm{Tm}$ and argon pressure, where both $\mathrm{T}$ and $\mathrm{Tm}$ are substrate temperature and coating material melting point, respectively. The $\mathrm{Tm}$ of $\mathrm{ZnO}$ is $2250 \mathrm{~K}$, and the value of $\mathrm{T} / \mathrm{Tm}$ is 0.23 at substrate temperature of $250{ }^{\circ} \mathrm{C}$.

We found the surface structures of $\mathrm{ZnO}$ films prepared by different Ar pressure are different. The grain size of $\mathrm{ZnO}$ decreased with $\mathrm{Ar}$ pressure increased, and the surface of $\mathrm{ZnO}$ films became more-rough as $\mathrm{Ar}$ pressure increased. This is because the energy of particles arriving at the surface decreases with increasing argon pressure, leaving less energy for surface diffuse due to collisions with more atoms $[9,10]$.

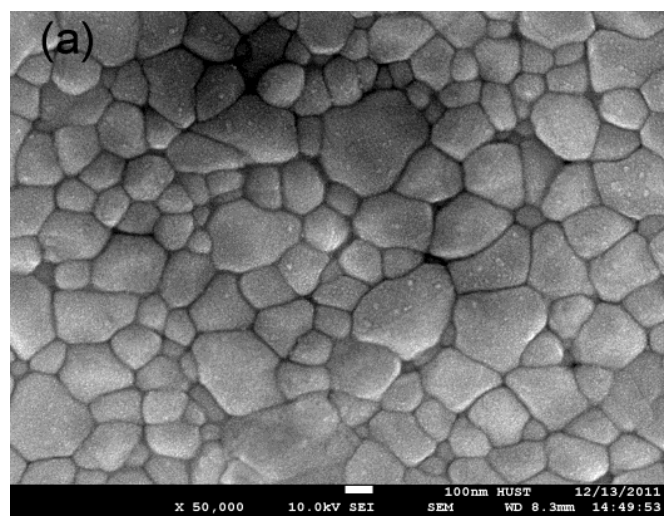



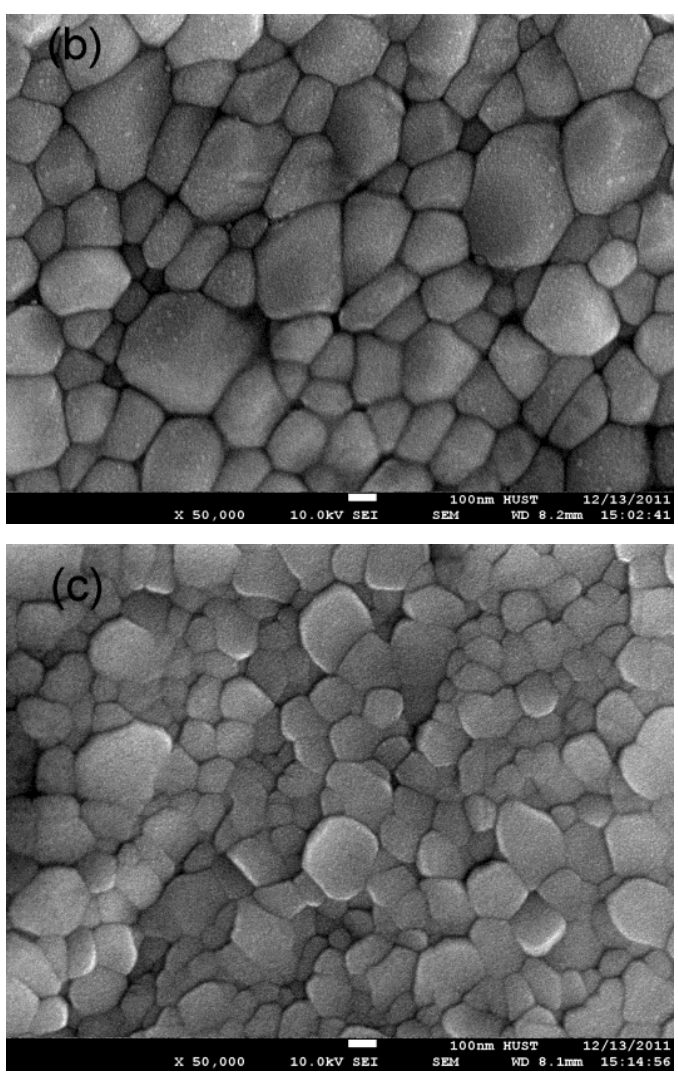

Fig. 3 The SEM micrographs of ZnO films deposited on $\mathrm{SiO}_{2} / \mathrm{Si}$ at $250{ }^{\circ} \mathrm{C}$, RF power $100 \mathrm{~W}$ and $\mathrm{Ar}$ pressure of (a) $P_{A r}=0.2 \mathrm{~Pa}$; (b) $P_{A r}=1.2 \mathrm{~Pa}$ and (c) $P_{A r}=3.2 P a$

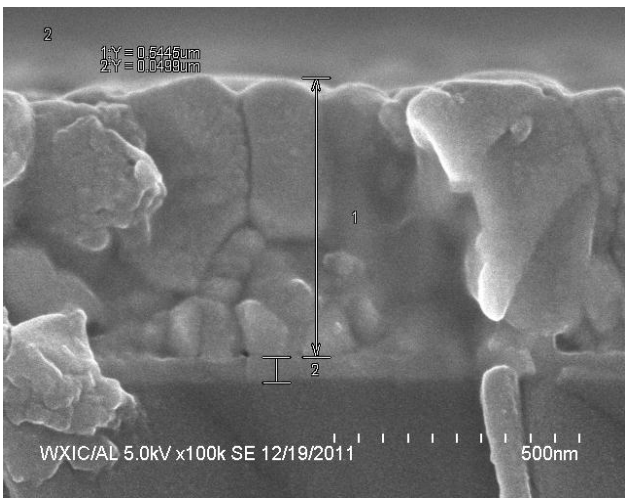

Fig. 4 Sectional view of the sample deposited for

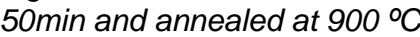

The thickness of $\mathrm{ZnO}$ film and that of $\mathrm{SiO}_{2}$ are shown in Fig. 4. The thickness of $\mathrm{ZnO}$ film is $544.5 \mathrm{~nm}$ while that of $\mathrm{SiO}_{2}$ is $50 \mathrm{~nm}$. The surface of the films is smooth and the grain of crystal is compact.

\section{Protein adsorption analysis}

Due to a high concentration of unsaturated bonds on $\mathrm{ZnO}$ films surface, $\mathrm{ZnO}$ films are suitable for the adsorption of proteins. In this paper, we fixed BSA to the activated $\mathrm{ZnO}$ films surface. AFM photographs of these samples have been taken to evaluate adsorption of BSA on $\mathrm{ZnO}$ films.

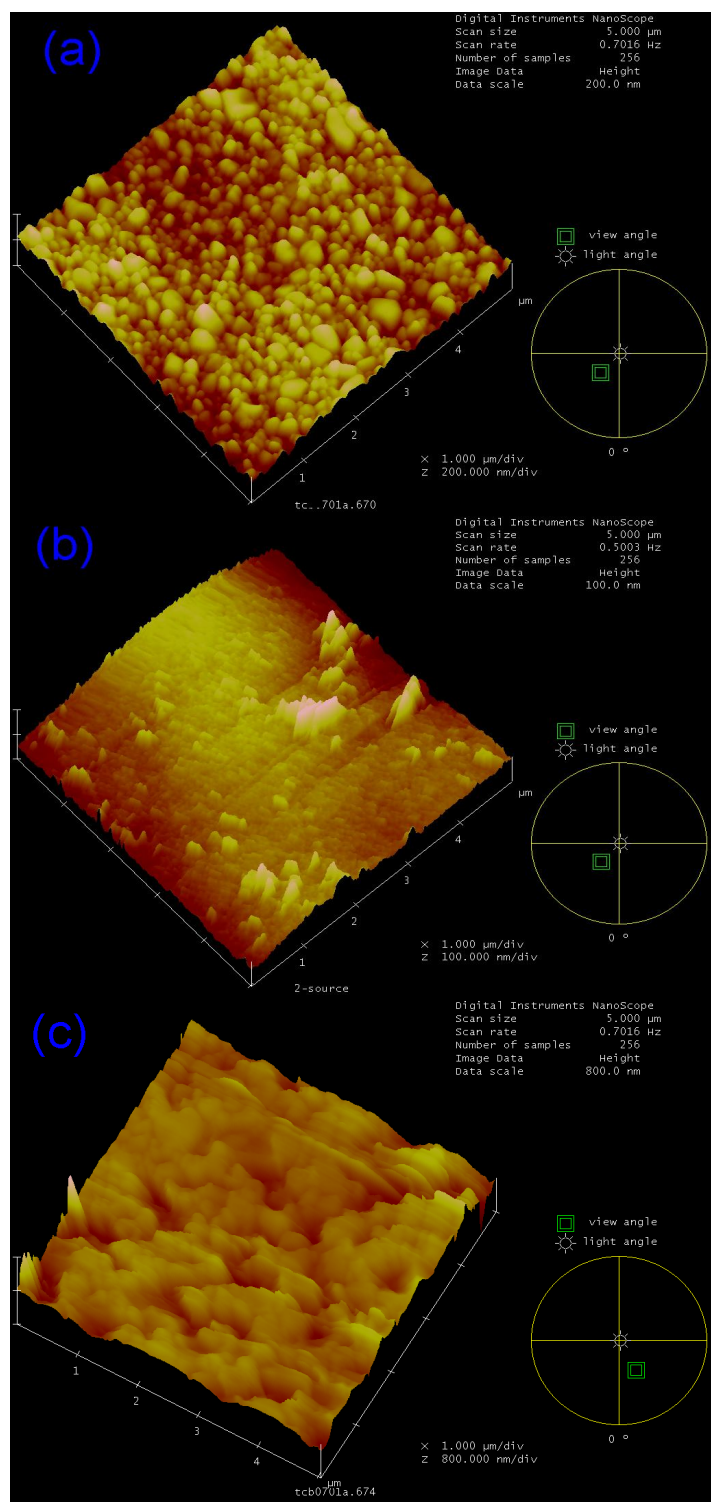

Fig. 5 AFM images of $\mathrm{ZnO}$ film and BSA (a) AFM image of $\mathrm{ZnO}$ film prepared at Ar pressure of 1.2 $\mathrm{Pa}$ (b) AFM image of BSA bound onto $\mathrm{ZnO}$ film prepared at Ar pressure of $0.2 \mathrm{~Pa}(\mathrm{c})$ AFM image of $B S A$ bound onto $\mathrm{ZnO}$ film prepared at Ar pressure of $1.2 \mathrm{~Pa}$

Fig. 5 is AFM images of the area of $5 \mu \mathrm{m} \times$ $5 \mu \mathrm{m}$ window on $\mathrm{ZnO}$ films. As shown in Fig. 5 (a), the grain size of $\mathrm{ZnO}$ prepared at $\mathrm{Ar}$ pressure of $1.2 \mathrm{~Pa}$ is about $100 \mathrm{~nm}-200 \mathrm{~nm}$, in accord with the grain size SEM observed before. Fig. 5 (b) is AFM image of BSA bound onto $\mathrm{ZnO}$ film prepared at $\mathrm{Ar}$ pressure of $0.2 \mathrm{~Pa}$. The surface became smooth, that is to say, BSA was fixed to surface of $\mathrm{ZnO}$ films. Fig.5 (c) is AFM image of BSA bound onto $\mathrm{ZnO}$ film prepared at Ar pressure of 1.2 Pa. As shown in Fig.5 (c), the loose porous structure of BSA is in accord with the structure of protein and illustrated that more BSA were adsorbed on $\mathrm{ZnO}$ films prepared at $\mathrm{Ar}$ pressure of $1.2 \mathrm{~Pa}$ than that on $\mathrm{ZnO}$ films prepared at Ar pressure 
of $0.2 \mathrm{~Pa}$. The thickness of BSA in Fig.5 (c) was also larger than that in Fig.5 (b). That is to say, the protein adsorption increased with grain size of $\mathrm{ZnO}$ decreased, and $\mathrm{ZnO}$ films with columnar crystalline structure adsorbed more proteins (Fig. 5).

As we explained above, the energy of particles arriving at the surface decreases with increasing argon pressure, leaving less energy for surface diffuse due to collisions with more atoms. In addition, adsorbed argon limitsalso the mobility of surface's atoms and selfshadowing effect becomes pronounced at high argon pressure. So the protein adsorption increased with $\mathrm{Ar}$ pressure increased, while the grain size of $\mathrm{ZnO}$ decreased with $\mathrm{Ar}$ pressure increased.

\section{Conclusion}

$\mathrm{ZnO}$ thin films deposited on $\mathrm{SiO}_{2}(50 \mathrm{~nm}) / \mathrm{Si}$ (100) substrates made by RF magnetron sputtering at substrate temperature of $250{ }^{\circ} \mathrm{C}$ and RF power of $100 \mathrm{~W}$ have been studied by change of Ar pressure. The influence of Ar gas pressure on characteristics of sputtered $\mathrm{ZnO}$ films was examined. The $X$-ray diffraction reveals that the films are oriented with their caxis perpendicular to the substrate surface, almost independent on the Ar pressure. The grain size of $\mathrm{ZnO}$ decreased with $\mathrm{Ar}$ pressure increased, and the surface of $\mathrm{ZnO}$ films became rougher as Ar pressure Increased. $\mathrm{ZnO}$ crystalline grain became columnar crystalline structure as Ar pressure increased. The protein adsorption decreased with grain size of $\mathrm{ZnO}$ decreased, and $\mathrm{ZnO}$ films with columnar crystalline structure adsorbed more proteins.

\section{Acknowledgements}

This work was financially supported by the Prog ram for New Century Excellent Talents in Unive rsity (Qiuyun Fu, 2010), China Postdoctoral Sci ence Foundation and the Natural Science Foun dation of China under Grant No. 61106081, No. 60772014 and No. 61006012.

\section{References}

[1] I. Sayago, M. Aleixandre, L. Are' s, M.J. Ferna' ndez, J.P. Santos, J. Gutie' rrez, M.C. Horrillo, Applied Surface Science 245 (2005) 273-280 doi:10.1016/j.apsusc.2004.10.035

[2] S. P. Singh, Sunil K. Arya, Pratibha Pandey, and B. D. Malhotra, APPLIED PHYSICS LETTERS 91, 063901 (2007), doi: $10.1063 / 1.2768302$

[3] Z. Yan, X. Y. Zhou, G. K. Pang, T. Zhang, W. L. Liu et al, Appl. Phys. Lett. 90, 143503 (2007); doi: 10.1063/1.2719149
[4] Krishnamoorthy, S., lliadis, A.A., Biosensors and Bioelectronics 24 (2008) 313-318; doi: 10.1016/j.bios.2008.04.011

[5] S. Krishnamoorthy, Thaleia Bei, Emmanouil Zoumakis, George P. Chrousos, Agis A. Iliadis, Biosensors and Bioelectronics 22 (2006) 707714. doi: 10.1016/j.bios.2006.02.020

[6] J. A. Thornton, J. Vac. Sci. Technol. 11(1974) 666.

[7] Qiuyun Fu, Pengcheng Yi, Dongxiang Zhou, Wei Luo, and Jianfeng Deng, Advanced Materials Research Vols. 418-420 (2012) pp 293-296 doi:10.4028/www.scientific.net/AMR.418-420.293

[8] Ang Wei, Liuhua Pan, Wei Huang, Materials Science and Engineering B 176 (2011) 1409- 1421, doi: 10.1016/j.mseb.2011.09.005

[9] G.S. Bales, A. Zangwill, J. Vac. Sci. Technol. 11 (1974) 671

[10] Dengyuan Song, Armin G. Aberle, James Xia, Applied Surface Science 195 (2002) 291-296, 